\title{
SOME PHYSICOCHEMICAL AND ORGANOLEPTIC PROPERTIES OF THE SHORT DOUGH WITH GOOSEBERRY POWDER
}

\author{
Sergiy BORUK ${ }^{1}$, Igor WINKLER ${ }^{2 *}$ \\ ${ }^{1}$ Department of Chemical Analysis, Food Safety and Testing, Institute of Biology, Chemistry and Bioresources, \\ Yu. Fedkovych National University of Chernivtsi, 2 Kotsyubynsky St., Chernivtsi, 58012, Ukraine \\ ${ }^{2}$ Department of Medicinal and Pharmaceutical Chemistry, Bucovina State Medical University, 2 Teatralna Sq., \\ Chernivtsi, 58002, Ukraine winkler@bsmu.edu.ua \\ *Corresponding author
}

Received 21 ${ }^{\text {th }}$ December 2020, accepted 20 $0^{\text {th }}$ March 2021

\begin{abstract}
Gooseberry powder can be used as an admixture to the confectionery short dough to improve its healthy food qualities and to increase the content of minerals and vitamins. Rheological, optical and some organoleptic properties of the dough were investigated for different contents of the powder. The viscosity of the gooseberry containing dough was found lower than that for the no gooseberry samples and, it was revealed that no optically active components moved from this admixture to the dough bulk.

Structuring of the gooseberry-containing dough was weaker than for the no-gooseberry materials and, in the former case, it took longer to restore the dough structure after it was damaged by the mechanical stress. Therefore, an overall fluidity of the gooseberry dough is some higher than that for the pure samples. The integral analysis of the organoleptic parameters of the pastry baked of the dough with different contents of gooseberry shows that no more than 2-3\% of the gooseberry powder should be added to the recipe to ensure a healthier consumption of the pastry and to preserve its consistency, taste and appearance.
\end{abstract}

Keywords: short dough; gooseberry; viscosity; organoleptic parameters; healthy food qualities

\section{Introduction}

Confectionery is a wide group of popular food products manufactured under different recipes, by various production technologies and possessing different consumerattractive qualities. Even though it cannot be considered as an essential food, the demand for this group of products is quite high and stable. Besides, confectionery is also important in the context of providing the human organism with energy and some vital components [1-5].

Dough products have several hundreds of types of items and are the most widespread and popular confectionery goods among different age groups. The short dough is made of flour, sugar, fats, some additional flavoring and aromatic additives [1]. This is quite a popular type of food embracing around a quarter of the dough confectionery market and known as a product with a significant energy value because of a high content of sugar and fat. On the other hand, the nutritional value of shortbread is rather low because its mineral and vitamins compositions are not balanced. This problem can be eliminated or mitigated by adding some components rich of the vegetable fibres and bioactive compounds [3]. This way, the nutritional quality of shortbread 
confectionery can be increased since such components provide immunity stimulation and are physiologically active. Moreover, they can also decrease the energy value of the confectionery to make it healthier and less fattening [5].

Gooseberry is a widely spread herb with bright, tasty and healthy fruits. It can be used as an additive to the shortbread to improve its quality, taste and consumer attractiveness in the abovementioned context [6,7].

In this paper, we report the results of the investigation of the influence of gooseberry powder on the rheological characteristics of the short dough, its organoleptic and some other characteristics.

\section{Experimental}

All investigations were carried out with the dough kneaded according to the traditional technology [1] using a mixture of the top grade flours of various Ukrainian brands obtained from a regular grocery store and, when needed, fine powder of the unbranded dried gooseberry fruits obtained from the same store.

Optical properties of the dough suspensions were investigated using the centrifugate separated from the dough after the 15 minutes long rotation at $1000 \mathrm{~s}^{-1}$. The spectral properties of the centrifugate were investigated using the SF-2 spectrophotometer by LOMO (St. Petersburg, Russia). In all cases, the absorbance of the filtrate was determined against distilled water.

All rheological investigations were performed using the cylindrical rotary viscometer "Rheotest-2" by VEB MLW (Leipzig, Germany) and the experimental guidelines attached to the device [8-12].

The gooseberry powder is a side component in the dough and, therefore, it will affect an inter-particle interaction between the particles of other dough components resulting in some changes in its viscosity and fluidity. On the other hand, some compounds can potentially be washed-out from the gooseberry powder during the kneading and transfer into the bulk of the dough.

All these questions had to be addressed by the above mentioned experimental investigations.

\section{Results and discussion}

It has been found that no gooseberry components were washed from its powder and transferred in the dough bulk. This result is grounded on the constancy of spectra recorded for the centrifugates obtained from the dough with and without an admixture of gooseberry (Fig. 1). As seen from the Fig.1, the pattern and peaks position for both samples are similar while some raise in the absorbance in the case of gooseberry-containing dough is caused by the natural decrease in the liquid transparency resulted by adding some more solute. Therefore, it seems that the optically active gooseberry components stay inside the powder, and none of them move to the dough bulk.

The dough is a complex and multicomponent heterogeneous system $[9,10]$ and any change in its composition can lead to unwanted shifts in its physicochemical parameters. The static and dynamic viscosity is an important characteristic of dough since it is usually transported at the bakeshops by various screw conveyors and other equipment, where these parameters are critical for effective functioning.

As seen from the results of rheological investigations (see Fig. 2), the effective viscosity of the dough is decreasing with increase in the displacement speed but, in case of the gooseberry-containing dough, it always stays below than that for the control dough across the entire range of the displacement speeds covered by this investigation.

As the displacement speed raises, the displacement forces make an initially chaotic distribution of the suspension particles more ordered by rearranging and lining them up along the flux direction. On the 
other hand, the interparticle aggregation is also weakening, and both these processes contribute to a decrease of the dough vis- cosity with raise in the displacement speed as seen in Fig. 2.

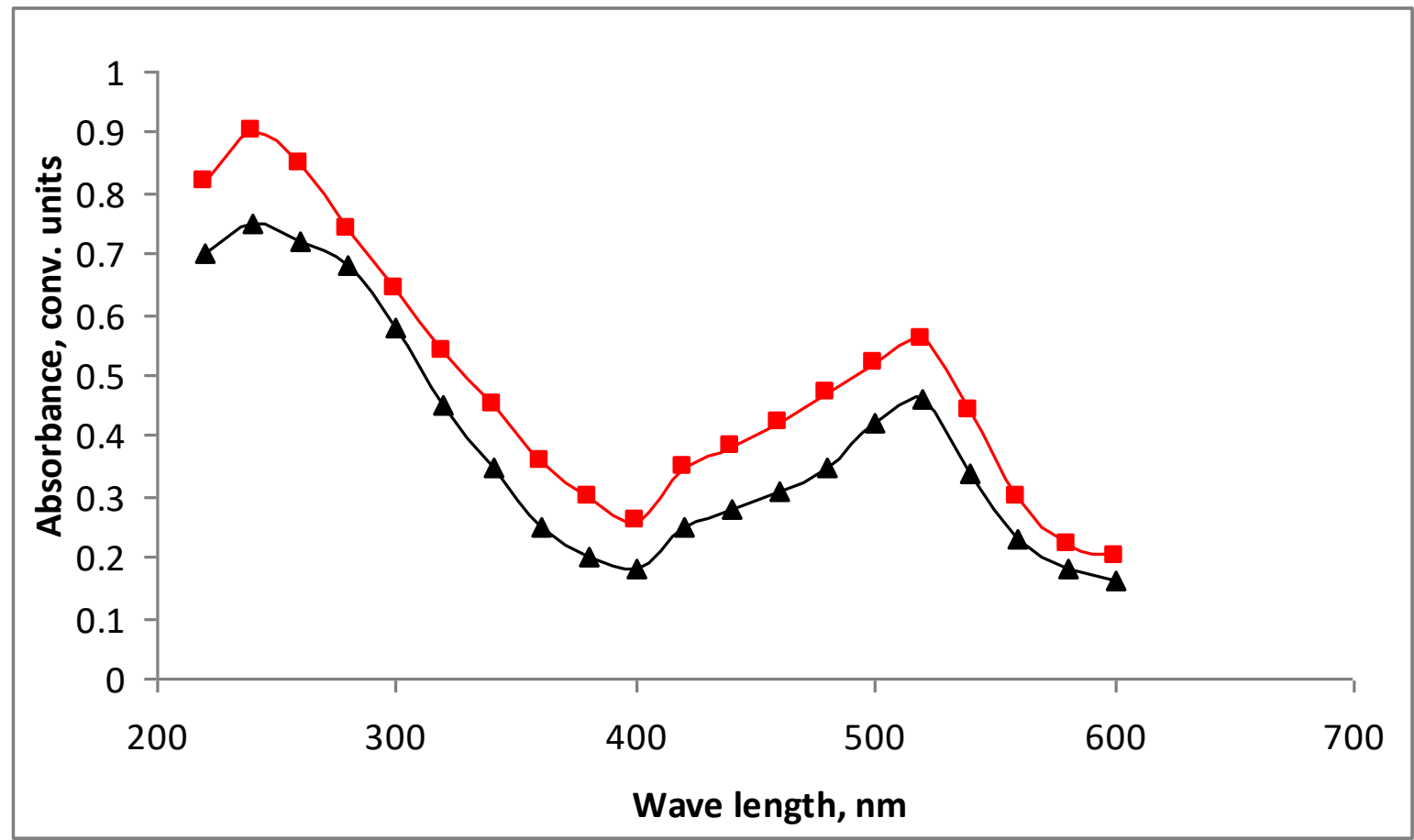

Fig. 1. Absorbance spectra of the centrifugates obtained from the samples of dough with ( $\square$ ) and without ( $\Delta$ ) a $5 \%$ admixture of the gooseberry powder.

It should also be mentioned that the dough viscosity is decreasing with a raise in the gooseberry powder content (see Fig. 3). This effect is caused by a weakening of the interparticle aggregation because of the introduction of the foreign gooseberry powder which cannot take part in structuring processes running in the dough with the flour particles $[8,9]$. The higher the content of the gooseberry powder, the more defective and less rigid structure is formed in the dough, which evidences itself through a decrease in its viscosity.

The ability of the dough to restore its pseudo-solid structure after it was destructed mechanically is one of the important operational characteristics since this parameter controls porosity of the baked pastry and smoothness of the technological transportation of the dough $[1,8]$. It has been found (see Fig. 2) that the damaging and then destruction of the pseudosolid structure of the dough occurs at the application of the shifting deformation caused by rotation of the viscometer cylinders [12]. As a result, at some rotation speed, a dependence of the dough viscosity on the rotation intensity interrupts, and it becomes almost independent on the rotation as it is characteristic for a Newtonian liquid. One can see that the dough turns into a Newtonian liquid at the rotation speed of around $100 \mathrm{~s}^{-1}$ for both dough samples (a further increase in the speed has only a minimal effect on the dough viscosity).

As external mechanical stress is decreasing, the dough structure is gradually restoring and it will return to the initial pseudosolid state. However, this process occurs not exactly the way as it did at the increase of the rotation speed. Therefore, a loop of hysteresis will appear for the dynamic dependence of the dough viscosity on the rotation speed. 


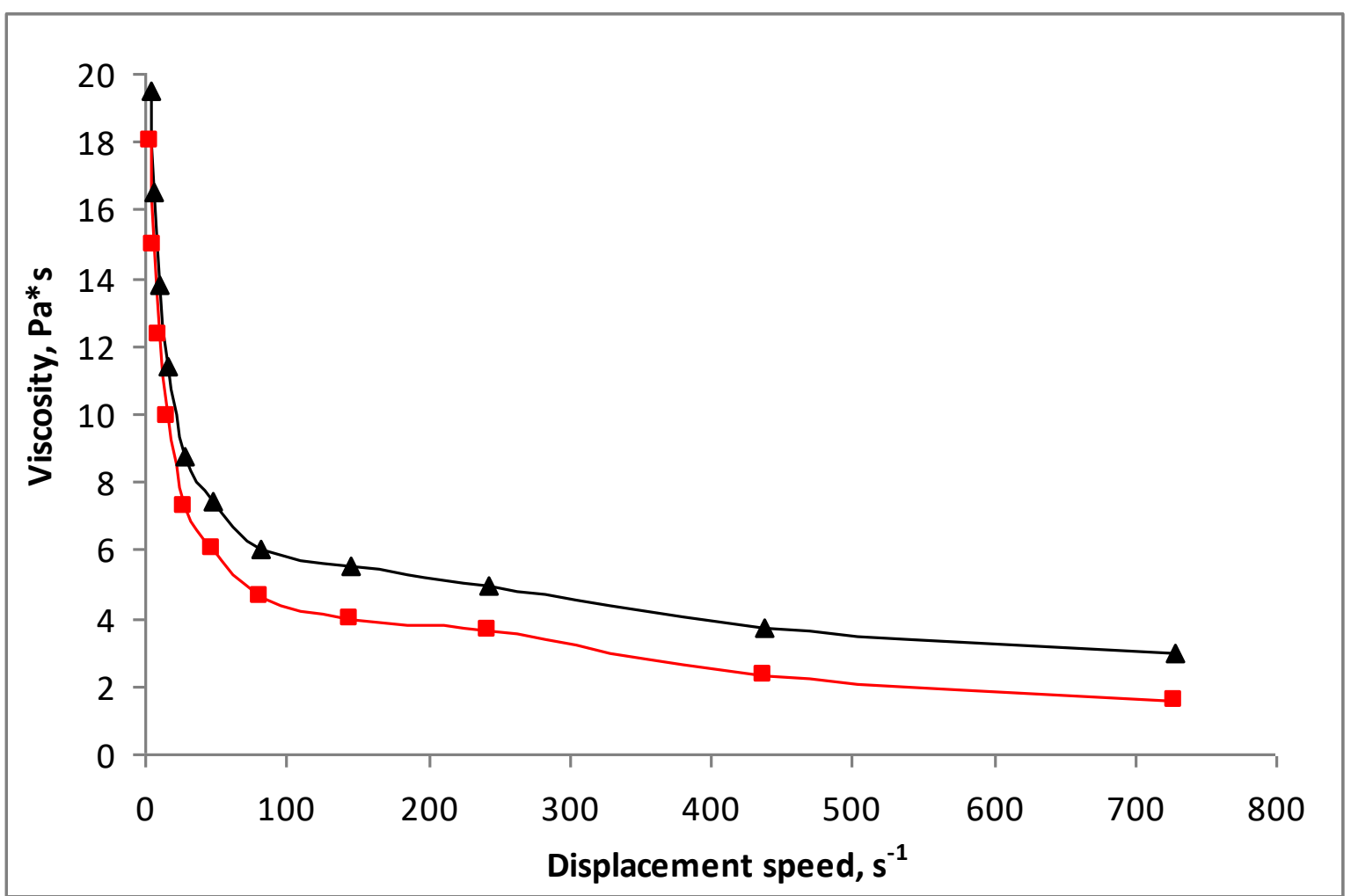

Fig. 2. Dependence of the short dough viscosity on the displacement speed for the $5 \%$ content of the gooseberry powder $(\square)$ and for the control sample $(\Delta$, no gooseberry).

These dependencies for the gooseberryfree and gooseberry-containing dough are shown in Fig. 4 and 5 respectively.

As the hysteresis loops seem different (the one for the gooseberry dough is wider than that for the control gooseberry-free sample), it can be concluded that the gooseberry powder actually influences the dough viscosity and its ability to restore the structure after mechanical stress. A comparison between Fig. 4 and 5 proves that a viscosity of the no-gooseberry dough is some higher than that for the gooseberry consisting sample at the same rotation speed and, on the other hand, in the former case, it restores sooner than in the latter one (compare the width of the loops shown in Fig. 4 and Fig. 5).

This relaxing character of the gooseberry powder can be caused by a difference into the surface hydrophilicity of the regular dough particles and the particles of gooseberry. This difference results in weaker bonding between these two types of the particles and, therefore, decreases viscosity and makes the particles' ability to bond into a structure weaker.

Both types of dough behave like the nonNewtonian systems since their effective viscosity within the laminar regime is not a constant, and it depends on the mechanical shifting force. There are two processes: structure deformation and restoration running simultaneously in the dough being affected by any mechanical stress, and the effective viscosity is the parameter representing a balance between them. The higher the content of gooseberries in the dough, the more the structure of the dough is shifted towards destruction, and the higher is the fluidity of the system. 


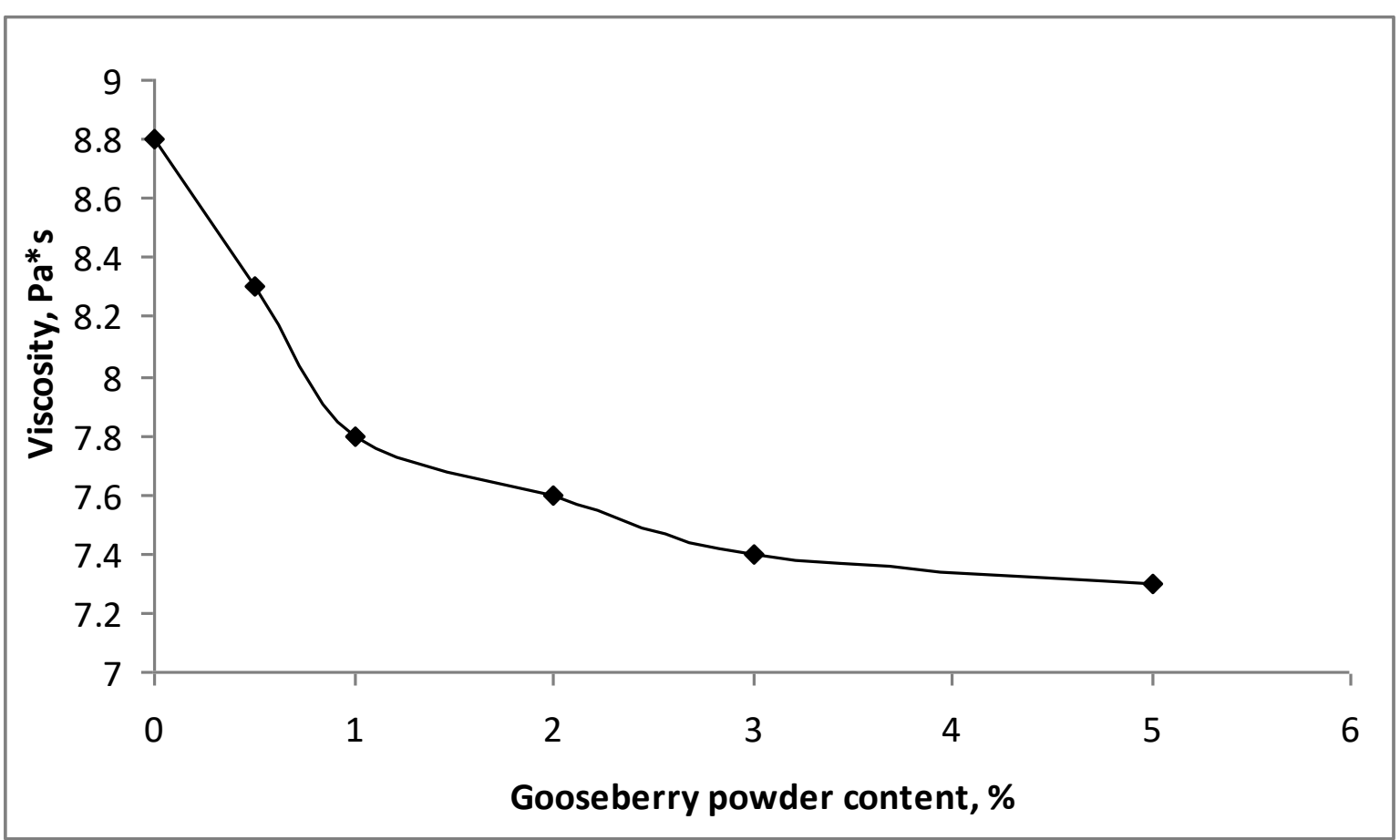

Fig. 3. Dependence of the dough viscosity on the gooseberry powder content at the displacement speed (rotation) $27 \mathrm{~s}^{-1}$.

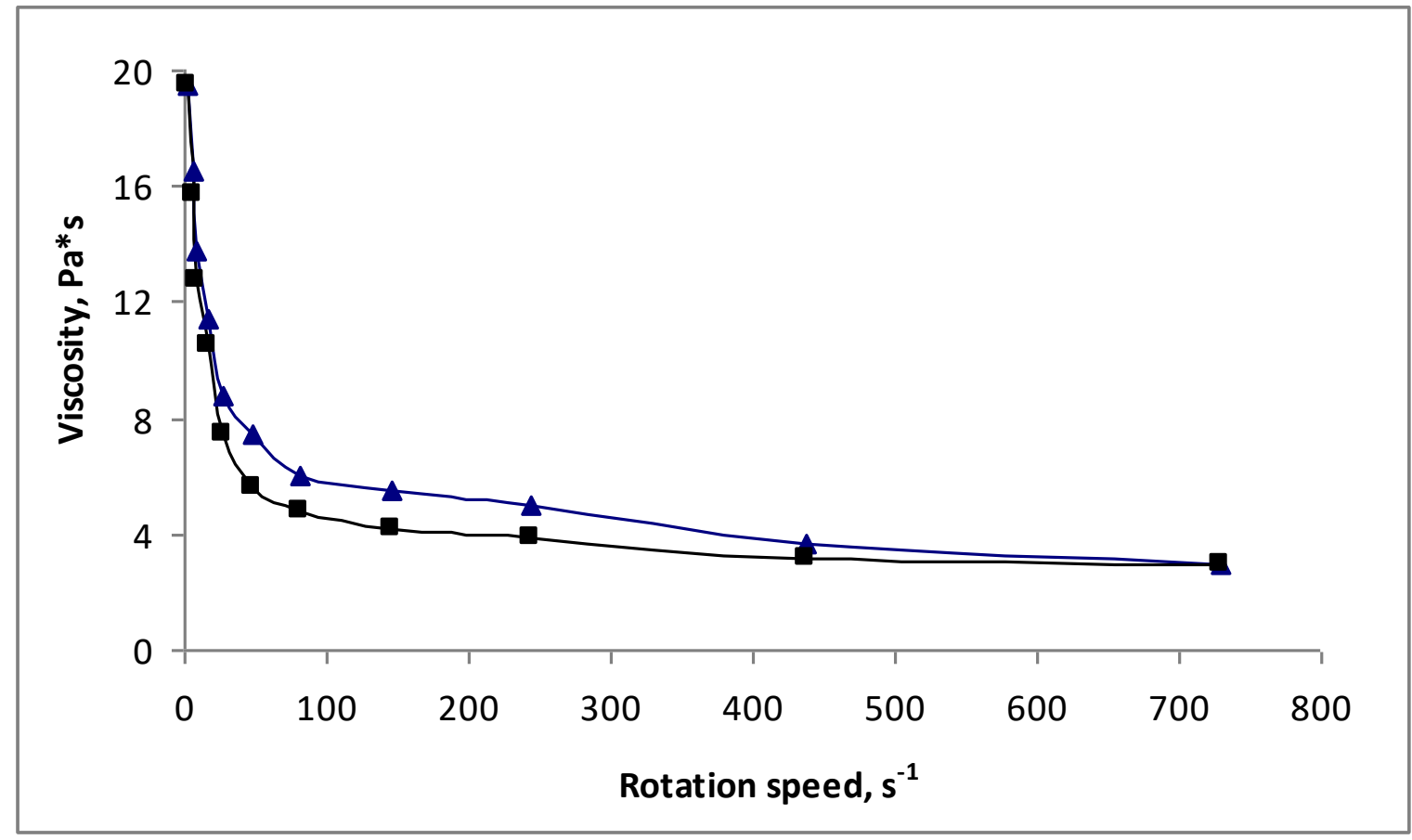

Fig. 4. The hysteresis loop for the short dough without an admixture of gooseberry. Upper line $(\Delta)$ corresponds to the viscosity at an increase of the rotation speed and the lower line (a) - at the decrease.

Sergiy BORUK, Igor WINKLER, Some physicochemical and organoleptic properties of the short dough with gooseberry powder, Food and Environment Safety, Volume XX, Issue 1-2021, pag. 5 - 12 


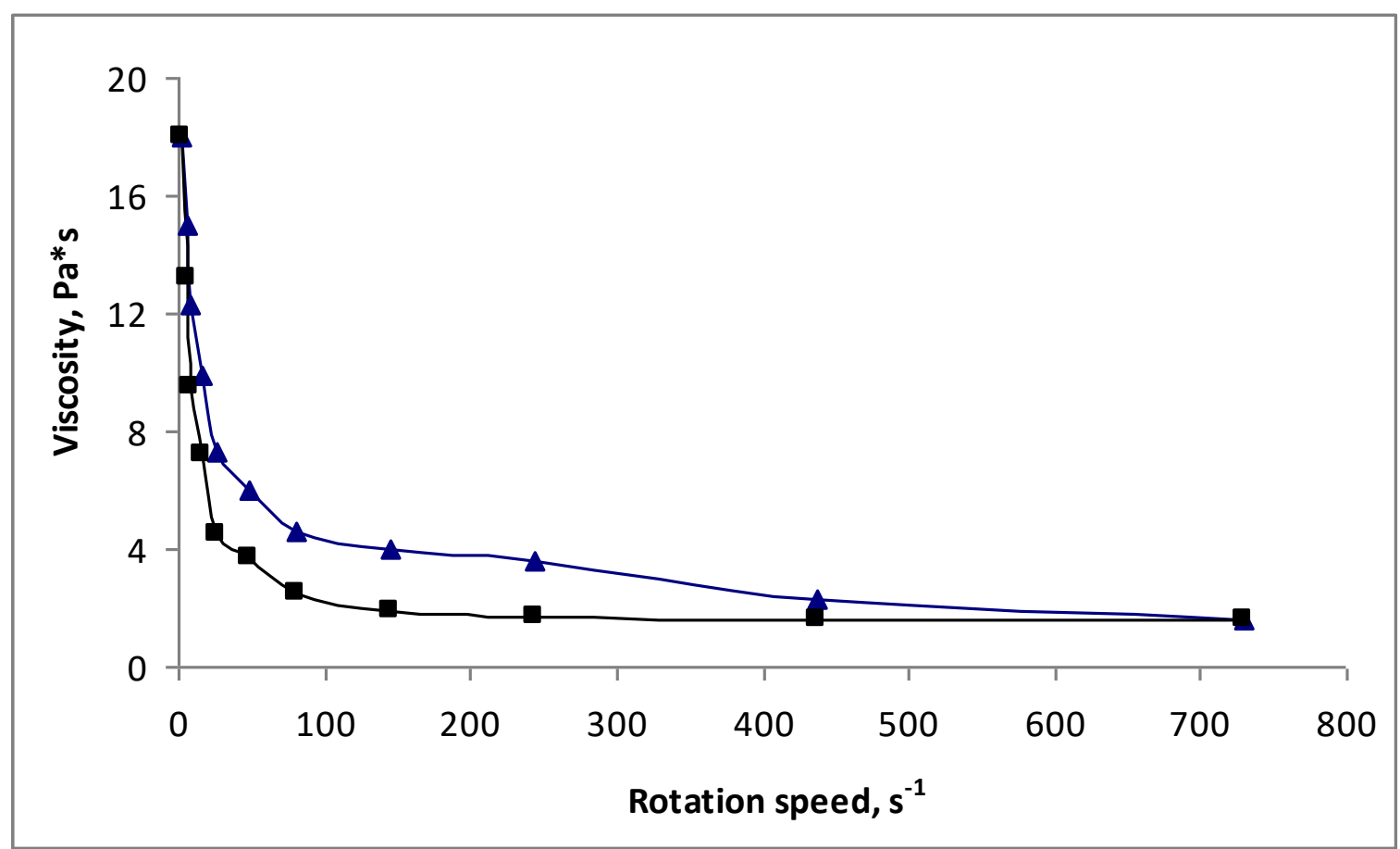

Fig. 5. The hysteresis loop for the short dough with $5 \%$ of gooseberry. Upper line $(\Delta)$ corresponds to the viscosity at an increase of the rotation speed and the lower line ( $\square$ ) - at the decrease.

Overall consumer qualities of the pastry were investigated by the following organoleptic parameters:

- appearance (shape, color, crust thickness, presence and width of the crust cracks);

- conditions of the pastry body (baking degree and uniformity, porosity, the occurrence of the dough voids; the occurrence of insufficient baking or under-kneaded spots);

- consistency;

- $\quad$ taste and smell (whether they inherent in the pastry, are there any side flavors or smells).

Four samples obtained by the addition of 1 , 2,3 and $5 \%$ of gooseberry and one control sample consisting of no gooseberry were baked for this organoleptic parameters investigation. All pastry was baked using the traditional technology of the short dough baking [3, 4]. In case of the gooseberryconsisting dough, this powder was added to the mixture together with the flour and before adding of the egg-sugar-butter component. Table 1 shows the overall organo- leptic parameters obtained from the blind tests involving 27 independent volunteers of both genders enrolled among the 18-21 years old students of Yu Fedkovych University of Chernivtsi studying food technologies. All of them tasted different numbered pastry samples being not informed of their composition.

The following three conditions were considered at the selection of the most optimal gooseberry content in the short dough: an amount of the powder should be sufficient to provide some improvement in the nutritional value, rheological characteristics of the dough shouldn't get significantly worsen, and an appearance of the pastry (crust and the pastry body color) should stay almost unchanged.

Basing on this approach, the following conclusion can be drawn from the abovementioned organoleptic tests:

- All organoleptic characteristics of the pastry with $1 \%$ of gooseberry stay the same or close to those of the control samples containing no gooseberry. However, no significant improve- 
ment of the nutritional quality can be expected in this case since the content of gooseberry is rather low;

All organoleptic characteristics also stay almost unchanged when the content of gooseberry reaches $2 \%$ although this amount is still considered as sufficient to improve the nutritional quality of pastry;
- $\quad$ As the nutritional qualities get further improvement for the pastry containing $3 \%$ of gooseberry, its organoleptic qualities turn worse;

- $\quad$ Finally, the above tendency continues for the pastry containing $5 \%$ of gooseberry and its organoleptic qualities go far below the appropriate standards.

Table 1

Comparative characteristics of some organoleptic parameters of the pastry consisting or not consisting some gooseberry powder

\begin{tabular}{|c|c|c|c|c|c|}
\hline Parameter & $\begin{array}{c}\text { Control } \\
\text { (no gooseberry) }\end{array}$ & $\begin{array}{l}\text { Pastry with } \\
1 \% \text { of goose- } \\
\text { berry }\end{array}$ & $\begin{array}{l}\text { Pastry with } \\
2 \% \text { of goose- } \\
\text { berry }\end{array}$ & $\begin{array}{l}\text { Pastry with } \\
3 \% \text { of goose- } \\
\text { berry }\end{array}$ & $\begin{array}{l}\text { Pastry with } \\
5 \% \text { of goose- } \\
\text { berry }\end{array}$ \\
\hline Appearance & $\begin{array}{l}\text { Smooth crust, } \\
\text { some small } \\
\text { cracks, uniform } \\
\text { color }\end{array}$ & $\begin{array}{c}\text { Smooth crust, } \\
\text { some small } \\
\text { cracks and } \\
\text { few surface } \\
\text { dots }\end{array}$ & $\begin{array}{l}\text { Uniform } \\
\text { crust, some } \\
\text { small cracks } \\
\text { and few sur- } \\
\text { face dots }\end{array}$ & $\begin{array}{l}\text { Uneven crust } \\
\text { with some } \\
\text { cracks and } \\
\text { well-seen in- } \\
\text { clusions of } \\
\text { gooseberry }\end{array}$ & $\begin{array}{c}\text { Uneven crust, } \\
\text { many cracks, } \\
\text { non-uniform } \\
\text { coloring and } \\
\text { well-seen in- } \\
\text { clusions of } \\
\text { gooseberry }\end{array}$ \\
\hline Color & $\begin{array}{l}\text { Light brown, } \\
\text { uniform }\end{array}$ & $\begin{array}{l}\text { Light brown, } \\
\text { uniform }\end{array}$ & $\begin{array}{l}\text { Light brown, } \\
\text { some not- } \\
\text { uniform }\end{array}$ & $\begin{array}{l}\text { Light brown, } \\
\text { uneven }\end{array}$ & $\begin{array}{c}\text { Dark-brown, } \\
\text { uneven }\end{array}$ \\
\hline Crust color & $\begin{array}{l}\text { Light yellow, } \\
\text { uniform }\end{array}$ & $\begin{array}{l}\text { Light yellow, } \\
\text { with few in- } \\
\text { clusions of } \\
\text { gooseberry }\end{array}$ & $\begin{array}{l}\text { Light yellow, } \\
\text { with some } \\
\text { gray tone }\end{array}$ & $\begin{array}{l}\text { Gray yellow, } \\
\text { with some } \\
\text { inclusions of } \\
\text { gooseberry }\end{array}$ & $\begin{array}{l}\text { Gray yellow } \\
\text { with numer- } \\
\text { ous inclusions } \\
\text { of gooseberry }\end{array}$ \\
\hline Consistency & $\begin{array}{l}\text { Brittle, with } \\
\text { little pores }\end{array}$ & $\begin{array}{l}\text { Brittle, with } \\
\text { little pores }\end{array}$ & $\begin{array}{l}\text { Brittle, with } \\
\text { little pores }\end{array}$ & $\begin{array}{l}\text { Brittle, with } \\
\text { little pores but } \\
\text { denser than } \\
\text { before }\end{array}$ & $\begin{array}{l}\text { Brittle, with } \\
\text { little pores but } \\
\text { denser than } \\
\text { before }\end{array}$ \\
\hline Smell & $\begin{array}{l}\text { Inherent in pas- } \\
\text { try }\end{array}$ & $\begin{array}{l}\text { Inherent in } \\
\text { pastry }\end{array}$ & $\begin{array}{l}\text { Inherent in } \\
\text { pastry }\end{array}$ & $\begin{array}{l}\text { Inherent in } \\
\text { pastry with } \\
\text { some bitter } \\
\text { note }\end{array}$ & $\begin{array}{c}\text { Inherent in } \\
\text { pastry with a } \\
\text { distinct bitter } \\
\text { note }\end{array}$ \\
\hline Taste & $\begin{array}{l}\text { Inherent, sweet, } \\
\text { no side smacks }\end{array}$ & $\begin{array}{l}\text { Inherent, } \\
\text { sweet, no side } \\
\text { smacks }\end{array}$ & $\begin{array}{l}\text { Inherent, } \\
\text { sweet, no side } \\
\text { smacks }\end{array}$ & $\begin{array}{l}\text { Inherent, } \\
\text { sweet with } \\
\text { light bitter- } \\
\text { ness }\end{array}$ & $\begin{array}{l}\text { Inherent, } \\
\text { sweet with a } \\
\text { distinct bit- } \\
\text { terness }\end{array}$ \\
\hline $\begin{array}{l}\text { Pastry body } \\
\text { conditions }\end{array}$ & $\begin{array}{l}\text { Well baked, no } \\
\text { under-kneads }\end{array}$ & $\begin{array}{l}\text { Well baked, } \\
\text { no under- } \\
\text { kneads }\end{array}$ & $\begin{array}{l}\text { Well baked, } \\
\text { no under- } \\
\text { kneads }\end{array}$ & $\begin{array}{l}\text { Well baked, } \\
\text { no under- } \\
\text { kneads }\end{array}$ & $\begin{array}{l}\text { Well baked, } \\
\text { no under- } \\
\text { kneads }\end{array}$ \\
\hline
\end{tabular}

Sergiy BORUK, Igor WINKLER, Some physicochemical and organoleptic properties of the short dough with gooseberry powder, Food and Environment Safety, Volume XX, Issue 1-2021, pag. 5 - 12 
Therefore, it can be concluded that 2-3\% of gooseberry seems the most optimal content of the gooseberry powder. This addition provides some appreciable improvement of the nutritional qualities while the organoleptic parameters stay almost unchanged.

\section{Conclusion}

It has been shown that the gooseberry powder can be used as an additive to some confectionery and pastry to improve their nutritional and healthy food qualities. An admixture of gooseberry ensures some decrease in the dough structuring ability and makes it more fluid. These effects should be taken into consideration at the construction and operation of the dough transportation and mechanical kneading equipment. No extra compounds exhibiting an optical activity are realized from the gooseberry powder into the dough bulk, therefore, the above physicochemical changes are caused by the presence of the gooseberry particles distributed among the flour and other components of the dough.

Since gooseberry causes some deterioration of the pastry organoleptic properties, it is not recommended to exceed $2-3 \%$ of its content. If this requirement is observed, some improvement of the nutritional qualities is achieved while the pastry appearance, taste, color and other properties remain almost unchanged.

\section{References}

[1]. A. V. PAVLOV, A digest of the recipes of the dough confectionery and pastry, Hydrometeoizdat, Moscow (1998) (In Russian)

[2]. N. YESHAK, Sensory evaluation and nutritional value of balady flat bread supplemented with banana peels as a natural source of dietary fiber, Annal. Agri. Sci., 61(2), 229-235 (2016)

[3]. A. VOLKOVA et al., Innovative technologies of using promising phyto-fortificants in bakery products of high nutritional value, IOP Conf. Ser.: Earth Environ. Sci., 403, 012119 (2019)

[4]. M. BIJLWAN et al, Recent developments in dough based bakery: a mini review, The Pharma Innov. J., 8(5), 654-658 (2019)

[5]. M. B. YERKEBAEV, Fundamentals of the food rheology. Textbook, ATU, Almaty (2006) (In Russian)

[6]. G. GRIFFITH, Prelude to good health: the organic wild gooseberry diet, Archway Publishing, USA (2017)

[7]. P. COMBRIS et al, Improvement of the nutritional quality of foods as a public health tool, Public Health, 125(10), 717-724 (2011)

[8]. R. BORWANKAR, C. F. SHOEMAKER (Eds), Rheology of food, Elsevier Applied Science UK, London (1992) doi: 10.1016/C2009-0-01131-3 [9]. M. F. KRAVCHENKO, O. L. ROMANOVSKA, S. D. BORUK, Rheological properties of the biscuit dough made of the flour "Health", Sci. Bull. National Food. Uni., 21(5), 69-74 (2015) (In Ukrainian)

[10]. M. F. KRAVCHENKO, O. L. ROMANOVSKA, S. D. BORUK, A comparative analysis of the rheological characteristics of the mixtures containing cacao and carob, Sci. Bill. Chernivtsi Uni., Series Chemistry, 753, 41-45 (2015) (In Ukrainian)

[11]. S BORUK, O. ROMANOVSKA, O. GERYCH, Structuring in the disperse systems of semolina and quinoa, Proc. of Lviv Chem. Readings, F29 (2017) (In Ukrainian)

[12]. VEB MLW: Guidelines to Rheotest-2. http://www.pochva.com/?content=3\&book_id=131 1 Accessed Nov. 23, 2020. 